Diah Novita, Nursama Heru Apriantoro, Penatalaksanaan Radioterapi Kanker Ovarium

Dengan Teknik IMRT Di Rumah Sakit X

\title{
PENATALAKSAAN RADIOTERAPI KANKER OVARIUM DENGAN TEKNIK IMRT DI RUMAH SAKIT X
}

\author{
Diah Novita ${ }^{1}$ \\ Politeknik Kesehatan Kementerian Kesehatan Jakarta II \\ Corresponding author E-mail : diah9811@gmail.com \\ Nursama Heru Apriantoro ${ }^{2}$ \\ Politeknik Kesehatan Kementerian Kesehatan Jakarta II
}

\begin{abstract}
ABSTRAK
Penelitian ini di latar belakangi oleh penyakit keganasan yaitu kanker ovarium yang merupakan kanker ginekologis terbanyak kedua yang diderita dan seringkali baru ditemukan ketika sudah stadium lanjut. Tujuan penelitian ini adalah untuk mengetahui dan mendeskripsikan prosedur penyinaran radioterapi menggunakan teknik IMRT (Intensity Modulated Radiation Therapy) di Instalasi Radioterapi Rumah Sakit X yang merupakan salah satu modalitas pengobatan kanker ovarium. Metode yang digunakan pada penelitian ini adalah kualitatif deskriptif dengan menggunakan satu sampel primer pada kasus kanker ovarium yang menggunakan teknik IMRT (Intensity Modulated Radiation Therapy), sampel ini diambil dari seluruh populasi kanker ovarium di Instalasi Radioterapi Rumah Sakit X. Instrumen penelitian yang digunakan berupa studi kepustakaan, observasi langsung, wawancara serta dokumentasi. Penelitian ini dilakukan pada bulan Mei 2021 di Instalasi Radioterapi Rumah Sakit X. Hasil yang dapat disimpulkan pada penelitian ini adalah prosedur penatalaksanaan radioterapi untuk kasus kanker ovarium menggunakan teknik IMRT (Intensity Modulated Radiation Therapy) di Instalasi Radioterapi Rumah Sakit $X$ meliputi beberapa prosedur yaitu: administrasi dengan membawa dokumen penunjang seperti hasil CT Scan/MRI/Bone Scan/USG, kemudian pasien melakukan konsultasi dengan dokter onkologi radiasi, melakukan persiapan-persiapan pasien, persiapan alat dan bahan, scanning di CT Simulator, proses perencanaan radiasi yang dilakukan di Treatment Planning System (TPS), proses verifikasi menggunakan alat verifikasi yaitu Electronic Portal Imaging Device (EPID) dan yang terakhir adalah penyinaran radiasi di ruang penyinaran dengan menggunakan pesawat radioterapi Linear Accelerator (LINAC) Elekta Synergy Platform.
\end{abstract}

Kata Kunci : Radioterapi, IMRT, Kanker Ovarium

\section{ABSTRACT}

This research background was by malignancy disease, which is ovarian cancer, this cancer is the second most common gynecological cancer suffered and is often discovered when it is in an advanced stage. The purpose of this study was to identify and describe the radiotherapy procedure using IMRT (Intensity Modulated Radiation Therapy) technique at the Radiotherapy Installation of Hospital $X$, which is one of the modalities of treatment for ovarian cancer. The method used in this research is descriptive qualitative using one primary sample in ovarian cancer cases using IMRT (Intensity Modulated Radiation Therapy) technique, this sample was taken from the entire population of ovarian cancer in the Radiotherapy Installation of Hospital X. The research instruments were used study literature, direct observation, interviews and documentation. This research was conducted in May 2021 at the Radiotherapy Installation of Hospital X. The results that can be concluded in this research are radiotherapy procedures for ovarian cancer cases using IMRT (Intensity Modulated Radiation Therapy) technique at the Radiotherapy Installation of Hospital $X$ are includes several procedures, there are: administration by bringing supporting documents such as CT Scan/MRI/Bone Scan/ USG, then the patient consults with a radiation oncologist, performs patient preparations, prepares tools and materials, scanning in the CT Simulator, radiation planning process is carried out at the Treatment Planning System (TPS), the verification process uses a verification device, namely the Electronic Portal Imaging Device. (EPID) and the last is radiation irradiation in the treatment room using Elekta Synergy Platform Linear Accelerator (LINAC) radiotherapy machine.

Keywords : Radiotherapy, IMRT, Ovarian Cancer 


\section{PENDAHULUAN}

Radioterapi atau disebut juga radiasi eksterna merupakan pengobatan kanker menggunakan radiasi pengion dengan sumber radiasinya memiliki jarak tertentu dari tubuh pasien. Penyinaran radiasinya dilakukan dengan pesawat linear accelerator (LINAC). Dilakukan sesuai dengan prinsip radioterapi yaitu untuk memberikan dosis semaksimal mungkin pada target dan seminimal mungkin pada jaringan sehat disekitarnya.(1)

Kanker ovarium adalah keganasan pada ovarium (indung telur) yang merupakan organ reproduksi perempuan dan kanker ovarium adalah kanker terbanyak kedua dari seluruh tipe kanker ginekologis. Menurut American Cancer Society, persentase kejadian kanker ovarium adalah sekitar $4 \%$ dari seluruh kanker yang diderita perempuan dan merupakan urutan kelima sebagai penyebab kematian akibat kanker. Sedangkan kanker ovarium ini biasanya ditemukan pada stadium lanjut, dikarenakan pada stadium awal biasanya tidak menimbulkan gejala.(2) Radioterapi itu sendiri bisa dijadikan sebagai salah satu pengobatan untuk penyakit kanker ovarium. Fasilitas radioterapi di Instalasi Radioterapi Rumah Sakit $X$ yaitu terdapat CT Simulator, Mouldroom, TPS, Pesawat radioterapi Linac Elekta.

Untuk mengetahui lebih jelas mengenai penatalaksanaan kanker ovarium, maka dari itu penulis melakukan penelitian dengan judul "Penatalaksanaan Radioterapi Kanker Ovarium dengan Teknik IMRT di Rumah Sakit X"

\section{METODE PENELITIAN}

Penelitian ini bersifat kualitatif deskriptif, menggunakan satu sampel dari seluruh populasi kanker ovarium di Instalasi Radioterapi Rumah Sakit X. Lokasi penelitian merupakan salah satu rumah sakit swasta di Jakarta, penelitian ini dilakukan pada bulan Mei 2021. Pengambilan sampel menggunakan metode non random sampling. Pengumpulan data dalam penelitian ini adalah dengan studi kepustakaan, observasi langsung dan wawancara dan dokumentasi.

\section{HASIL DAN PEMBAHASAN}

Sampel merupakan pasien penderita kanker ovarium dengan kasus kekambuhan (relaps) yang melakukan treatment radioterapi teknik IMRT (Intensity Modulated Radiation Therapy), fraksinasi sebanyak 25x yaitu dengan dosis 2 Gy/fraksi, sehingga total dosis radiasi yang diberikan sebanyak $50 \mathrm{~Gy}$, menggunakan energi radiasi $10 \mathrm{mV}$ (megaVolatage) dengan alat penyinaran berupa pesawat Linac Elekta Synergy Platform. Alat dan Bahan dalam penyinaran radioterapi ini adalah sebagai berikut: CT Simulator, Pesawat Linac Elekta Synergy Platform, Masker Pelvis, Base Plate, Leg Fixator sebagai alat immobilisasi pasien, spidol dan micropore sebagai penanda titik references.

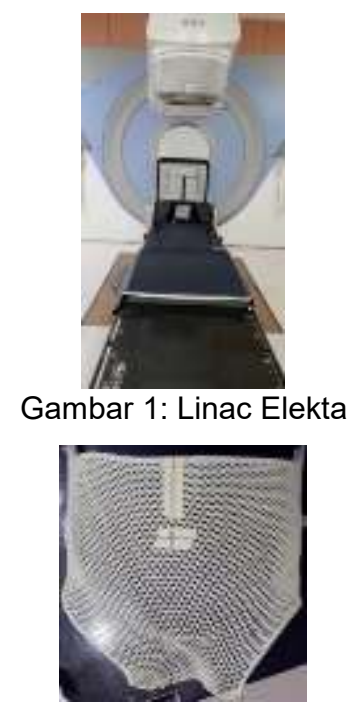

Gambar 2: Masker Pelvis

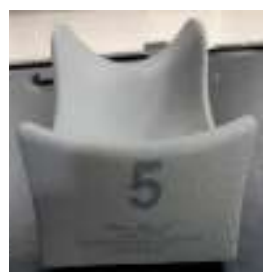

Gambar 3: Bantal Kepala No.5 


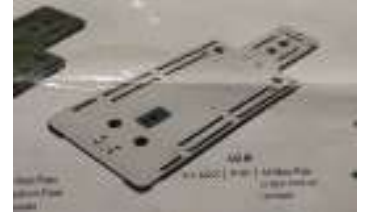

Gambar 4: Base Plate

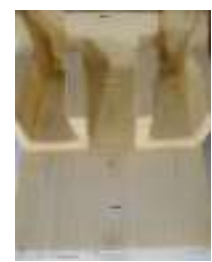

Gambar 5: Leg Fixator

Prosedur Penatalaksanaan Radioterapi di Instalasi Radioterapi Rumah Sakit X

Alur Pasien di Instalasi Radioterapi :

a. Pertama pasien / keluarga pasien / petugas datang ke registrasi radioterapi dengan membawa surat pengantar untuk radiasi dan membawa dokumen penunjang seperti hasil lab, patologi serta hasil CT Scan / MRI / Bone scan/USG.

b. Kemudian pasien membuat perjanjian dengan dokter onkologi untuk konsultasi dengan dokter apakah pasien dapat dilakukan tindakan radiasi atau tidak. Dalam konsultasi tersebut, dokter onkologi menentukan Stadium dan tujuan dilakukan penyinaran (kuratif/paliatif), penentuan teknik penyinaran serta dosis yang diberikan dan pasien mendapatkan penjelasan tentang pemeriksaan.

c. Setelah dokter mengkonfirmasi bahwa pasien melakukan tindakan radiasi, pasien melakukan pendaftaran di loket pendaftaran radioterapi untuk diberitahukan tentang rincian biaya serta melakukan perjanjian administrasi radioterapi untuk jadwal selanjutnya.

d. Setelah pasien selesai dengan administrasi, pasien melakukan tindakan Simulator atau CT Simulator terlebih dahulu sebelum melakukan tindakan penyinaran.
Adapun prosedur diruangan CT Simulator kasus CA ovarium adalah sebagai berikut :

- Identifikasi pasien

- Minta pasien untuk minum air 15 menit sebelum CT planning dilakukan (hal ini juga berlaku pada saat sebelum penyinaran di treatment room)

- Panaskan waterbath dan rendam masker didalamnya

- Instruksikan pasien untuk supine diatas meja pemeriksaan dan atur posisinya agar simetris

- Pasang masker pelvis pada tubuh pasien dan atur laser sesuai titik references

- Gambar titik referensi sesuai pada petemuan ketiga titik laser dengan spidol biru di tubuh pasien dan pasang marker tepat dipertengaham masingmasing titik

- Lakukan scanning dengan mengatur batas atas dan batas bawah

- Setelah scanning, radioterapis mengambil foto pasien posisi pasien

- Lepaskan masker, marker dan alat immobilisasi dari tubuh pasien dan pasien di perbolehkan keluar dari ruangan.

- Kemudian kirim status pasien dan hasil scanning ke TPS

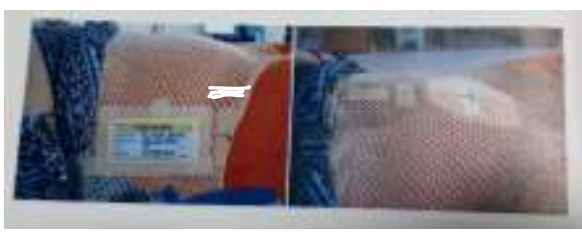

Gambar 6: Posisi pasien di CT Simulator

e. TPS (Treatment Planning System) oleh Dokter Onkologi Radiasi dan Fisika Medik

f. Setelah selesai membuat kontur dan planning, Pasien akan di verifikasi menggunakan EPID (Electronic Portal Imaging Device) diruang penyinaran pada hari pertama disinar, untuk menyesuaikan titik origin dan isocenter supaya penyinaran sesuai pada target/tumor. 
g. Kemudian Radioterapis menginput data pasien.

h. Tindakan Penyinaran di treatment room

\section{Prosedur Penyinaran di Treatment Room:}

- Klik select patient dan cari nama pasien di komputer mosaiq, periksa nama dan nomor RM, jika sudah sesuai, klik treat.

- Setelah siap, panggil pasien dengan menanyakan pertanyaan terbuka sebelum dilakukan penyinaran.

- Persiapkan meja pemeriksaan dan aksesoris lainnya

- Atur posisi pasien yaitu supine diatas base plate, pasang masker dan alat immobilisasi

- Atur titik sentrasi laser sesuai dengan apa yang sudah ditandai oleh petugas radioterapi pada tubuh pasien saat setelah diverfikasi.

- Atur sudut gantry linac sesuai.

- Beritahu pasien bahwa penyinaran sudah siap dilakukan.

- Setelah itu, tutup pintu rapat, nyalakan indicator penyinaran dan lakukan penyinaran.

- Isi data status penyinaran pasien harian dan kartu penyinaran pasien dan tanda tangan RTT

\section{KESIMPULAN}

Radioterapi atau disebut juga radiasi eksterna merupakan salah satu modalitas pengobatan kanker menggunakan radiasi pengion dengan sumber radiasinya memiliki jarak tertentu dari tubuh pasien. Penyinaran radiasinya dilakukan dengan pesawat linac Kanker ovarium adalah keganasan pada ovarium (indung telur) yang merupakan organ reproduksi perempuan dan kanker ovarium adalah kanker terbanyak kedua dari seluruh tipe kanker ginekologis. Kanker ovarium jenis epitel merupakan jenis yang sering ditemukan, sedangkan yang paling jarang ditemukan adalah germinal yang mana jenis ini dapat terjadi di remaja dan perempuan muda dengan usia 16-20 tahun.

Prosedur penyinaran di Instalasi Radioterapi RS X untuk pasien yang akan di radioterapi dimulai dari administrasi dengan membawa dokumen penunjang, kemudian pasien melakukan konsultasi dengan dokter spesialis onkologi radiasi, lalu dijadwalkan CT planning, yang kemudian hasil scanning dikirim ke TPS. Setelah mendapatkan persetujuan dari dokter onkologi radiasi maka dilakukan tindakan radioterapi menggunakan pesawat LINAC Elekta.

\section{SARAN}

$\begin{array}{clr}\text { Penulis } & \text { berharap agar } \\ \text { penatalaksanaan } & \text { radioterapi dapat }\end{array}$ dilaksanakan dengan tetap memperhatikan prinsip radioterapi, selain itu untuk menambah keakuratan pada hal tersebut, penulis menyarankan untuk melakukan penandaan titik referensi pada tubuh pasien untuk lebih meminimalkan terjadinya pergeseran dan untuk penelitian selanjutnya dapat melakukan penelitian dengan teknik radioterapi yang lainnya.

\section{DAFTAR PUSTAKA}

Susworo R, Kodrat H. Radioterapi : DasarDasar Radioterapi Tata Laksana Radioterapi Penyakit Kanker. II. Jakarta: Penerbit Universitas Indonesia (UI-Press); 2017. 342 p.

Rahmawati H, ER D, Pakasi RD. Kanker Ovarium Disgerminoma. Indones J Clin Pathol Med Lab. 2016;19(1):51.

Fachlevy AF, Abdullah Z, Russeng SS, Fachlevy AF. Faktor risiko kanker ovarium di RSUP Wahidin Sudirohusodo Makassar. RSUP Wahidin Sudirohusodo Makassar. 2011;

Mussardo G. Kanker Ovarium. Stat F Theor [Internet]. 2019;53(9):1689-99. Available from: https://sinta.unud.ac.id/uploads/doku men_dir/b24adde57acc93fe1519b8d b71314748.pdf

Trihandini I, Nurrika D. Analisis Ketahanan Hidup Penderita Kanker Ovarium Epithelial di RS Dharmais Jakarta. J Kesehat Masy Nas Vol 5, No 3, Desember 2010. 2010;5:139-44. 
Fields EC, McGuire WP, Lin L, Temkin SM. Radiation treatment in women with ovarian cancer: Past, present, and future. Front Oncol. 2017;7(AUG).

li BAB, Teori L. (Stephens, O Frederick, 2009). 2009;17-38.

Xu D, Li G, Li H, Jia F. Comparison of IMRT versus $3 \mathrm{D}-\mathrm{CRT}$ in the treatment of esophagus cancer. Med (United States). 2017;96(31):1-7.

Yonekura Y, Tsujii H, Hopewell JW, Ortiz López P, Cosset JM, Paganetti $\mathrm{H}$, et al. Radiological protection in ion beam radiotherapy: practical guidance for clinical use of new technology. Ann ICRP. 2015;45:13847.

Kodrat H, Novirianthy R. Prinsip Dasar Radioterapi. Med J Kedokt Indones. 2016;6(XLI):318-23.

Cherry P, Duxbury AM. Practical Radiotherapy: Physics and Equipment, 2nd Edition. London: Wiley-Blackwell; 2009. 304 p.

Siti A, Adi K, Fisika J, Sains F, Diponegoro U. PEMBUATAN PROGRAM REKONSTRUKSI KONTUR CITRA 3D PADA ORGAN MENGGUNAKAN MATLAB 2008a. Youngster Phys J. 2013;2(4):213-20. 